\title{
Effect of Shading on Series and Parallel Connected Solar PV Modules
}

\author{
Ramaprabha Ramabadran (Corresponding author) \\ Department of EEE, SSN College of Engineering \\ Rajiv Gandhi Salai, Chennai -603 110, Tamilnadu, India
}

Tel: 91-44-2727-5064Ｅ-mail: ramaprabhasuresh@gmail.com

\author{
Badrilal Mathur \\ Department of EEE, SSN College of Engineering \\ Rajiv Gandhi Salai, Chennai- 603 110, Tamilnadu, India \\ Tel: 91-44-2727-5064 E-mail: mathur1941@yahoo.co.in
}

\begin{abstract}
The aim of this study is to investigate the harmful effects of partial shading of series and parallel connected Solar PV modules and compare their performance. In order to find which connection is less susceptible to partial shading effects, a PSPICE simulation model that represents 36 cells PV module under partial shaded conditions has been used to test several shading profiles and results are presented.
\end{abstract}

Keywords: Partial Shading, Power loss, Heat dissipation, Utilisation factor, Series and Parallel combination

\section{Nomenclature}

\begin{tabular}{|c|c|}
\hline V and I & - Array Voltage and Array current respectively \\
\hline $\mathrm{I}_{\mathrm{L}}$ & - The current generation by absorption of photons at short circuit \\
\hline $\mathrm{R}_{\mathrm{se}}$ and $\mathrm{R}_{\mathrm{sh}}$ & - Series and Shunt resistances in the equivalent circuit of the module \\
\hline $\mathrm{I}_{\mathrm{o}}$ & - Diode reverse saturation current in the equivalent circuit of the module \\
\hline $\mathrm{V}_{\mathrm{t}}$ & - $\quad$ Thermal voltage $(=\mathrm{nkT} / \mathrm{q})$ \\
\hline $\mathrm{n}$ & - $\quad$ Diode ideality factor $(1<\mathrm{n}<2$ for a single solar cell $)$ \\
\hline $\mathrm{k}$ & - Boltzman's constant $(=1.381 \times 10-23 \mathrm{~J} / \mathrm{K})$ \\
\hline q & - $\quad$ Electron charge $(=1.602 \times 10-19 \mathrm{C})$ \\
\hline $\mathrm{T}$ & - Temperature in Kelvin \\
\hline $\mathrm{F}$ & $\begin{array}{l}\text { Ratio of the photo absorption current generated by the shaded illuminated cells to that } \\
\text { generated by the fully illuminated cells }\end{array}$ \\
\hline $\mathrm{v}_{\mathrm{s}}$ & - Voltage across one of the shaded illuminated cells \\
\hline $\mathrm{v}_{\mathrm{i}}$ & - Voltage across one of the fully illuminated cells \\
\hline a & - Number of cells under full illumination \\
\hline $\mathrm{b}$ & - Number of cells under shaded illumination \\
\hline $\mathrm{P}_{\mathrm{Ds}}$ & - Power dissipated by a cell under shaded illumination \\
\hline$P_{\max (\text { array })}$ & - Maximum power produced by the array \\
\hline$P_{\max (\operatorname{module} 1)}$ & - $\quad$ Maximum power produced by the fully illuminated module-1 \\
\hline$P_{\max (\operatorname{module} 2)}$ & - $\quad$ Maximum power produced by the shaded illuminated module- 2 \\
\hline 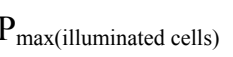 & - Maximum power produced per cell by the fully illuminated cells in module- 2 \\
\hline$P_{\max (\text { shaded cells) }}$ & - $\quad$ Maximum power produced per cell by the shaded illuminated cells in module- 2 \\
\hline 'i' and 's' & $\begin{array}{l}\text { Additions subscripts indicate the parameters of fully illuminated cells and shaded illuminated } \\
\text { cells }\end{array}$ \\
\hline
\end{tabular}




\section{Introduction}

A number of series/parallel connected PV modules are used to form a solar array for a desired voltage and current level. Performance of a series connected string of solar cells is adversely affected if all its cells are not equally illuminated (partially shaded). In a solar array spread over vast area, it is likely that shadow may fall over some of its cells due to tree leaves falling over it, birds or bird litters on the array, shade of a neighboring construction etc. In a series connected string of cells, all the cells carry the same current. Even though a few cells under shade produce less photon current but these cells are also forced to carry the same current as the other fully illuminated cells. The shaded cells may get reverse biased, acting as loads, draining power from fully illuminated cells. If the system is not appropriately protected, hot-spot problem (Quaschning and Hanitsch, 1996) can arise and in several cases, the system can be irreversibly damaged.

Nowadays there is an increasing trend to integrate the solar PV arrays at the design level in the building itself. In such cases it is difficult to avoid partial shading of array due to neighboring buildings throughout the day in all the seasons. This makes the study of partial shading of modules a key issue. In recent years, the impact of partial shading on the PV array performance has been widely discussed (Herrmann et al, 1997; Kaushika and Gautam, 2003; Klenk et al, 2002; Woyte et al, 2003)

With a physical Solar PV module it is difficult to study the effects of partial shading since the field testing is costly, time consuming and depends heavily on the prevailing weather condition. Moreover it is difficult to maintain the same shade under varying numbers of shaded and fully illuminated cells throughout the experiment. However it is convenient to carryout the simulation study with the help of a computer model. In most of the studies (Hans.S.Rauschenbach et al., 1971; M.C.Alonso et al., 2006; M.C.Alonso-Garcia, 2007; Engin Karatepe et al., 2007), the effect of partial shading in reducing the output power of the solar PV array has been discussed. But it is little attention is given how the power dissipated by the shaded cells is affecting the array life and utilization of the array for the worst shaded case. This work is mainly concentrated to study the harmful effects of the shading patterns in series and parallel connected modules.

A PSPICE model to simulate V-I (Voltage-Current) and V-P (Voltage-Power) characteristics of a PV module consisting of 36 cells in series has been developed. The array that consists of two modules is considered in this study. The array is either series or parallel combination of two modules. One of the modules in the combination is considered to be with uniform illumination and other module is partially shaded. The array is used to study the effect of shade on varying number of cells on the power output of the shaded module and stresses on the shaded illuminated cells under various illumination levels.

\section{PSPICE Equivalent Circuit for Solar Photovoltaic module}

An equivalent circuit of a SPM consisting of 36 cells in series with uniform illumination, module-1 including parasitic series and shunt resistances is shown in Figure.1. The output current $I_{m l}$ through the load resistance is then given by equation 1 .

$$
I_{m 1}=I_{L}-I_{o}\left\{\exp \left(\frac{V_{m 1}+I_{m 1} R_{s e}}{V_{t}}\right)-1\right\}-\frac{\left(V_{m 1}+I_{m 1} R_{s e}\right)}{R_{s h}}
$$

The circuit of Figure.1 is simulated using PSPICE software (www.cadence.com). The PSPICE model is validated against the practical characteristics obtained using Electronic load (Yingying Kuai and S. Yuvarajan, 2006; Ramaprabha and B.L.Mathur, 2008). Parameters like diode ideality factor $\mathrm{n}$, diode reverse saturation current $I_{o}$, shunt and series resistances $R_{s h}$ and $R_{s e}$ were tuned to match the characteristics of the PSPICE model with that obtained for realistic module and specifications supplied by the manufacturer. For this study Solkar Model 3712/0507 that consists of 36 cells in series is used. Specifications of the solar cell and module used in this simulation study are given in Table.1.

All the cells of the module are assumed to be identical. Temperature differences between shaded and unshaded cells and reverse breakdown effects in shaded cells are neglected. Values of $R_{\text {ses }}$ and $R_{\text {shs }}$ have been assumed to be constant for a particular value of F. These assumptions will not substantially affect the conclusions drawn. The array is formed by connecting the modules in series or parallel.

\section{Effect of Shadow on the module}

A shadow falling on a group of cells will reduce the total output by two mechanisms:1) by reducing the energy input to the cell, and 2) by increasing energy losses in the shaded cells. Problems become more serious when shaded cells get reverse biased. In Figure.2, a group of cells under full illumination is connected in series with another group of cells under shaded illumination, module-2. The photon current of fully illuminated cells $I_{L i}$ is high compared with that of the shaded illuminated cells $I_{L s}$. If the module current $I_{m 2}<I_{L s}$, diode $\mathrm{D}_{\mathrm{s}}$ is forward biased and there is no risk for the shaded cells. But if $I_{m 2}>I_{L s}$, then the diode current $I_{D s}=I_{L s}-I_{m 2}$ flow through the diode in the reverse direction. Reverse biased diode $\mathrm{D}_{\mathrm{s}}$ offers high resistance will consume power and will significantly reduce the load current $I_{m 2}$ itself. The point B 
will assume negative potential. If the difference in illumination levels is high, $\mathrm{D}_{\mathrm{s}}$ may get damaged due to overheating. (Ramaprabha and B.L.Mathur, 2008)

\section{Analysis of Parameters affecting the performance of Series and Parallel Connected SPV modules under Partial Shading}

To form an array the equivalent circuit shown in Figure. 1 and Figure. 2 is combined in series or parallel. For this study module- 1 is considered to be fully illuminated and module- 2 is under shaded condition. i.e. Figure. 1 indicates module- 1 and Figure. 2 indicates module-2. The series and parallel connected modules are shown in Figure.3.

The photo current generated by the shaded illuminated cell in module-2 is $F I_{L}$, where $F$ is the ratio of photo current generated by the shaded cell to that of the fully illuminated cell. $F=0$ means, fully shaded and $F=1$ means fully illuminated. In module-2, when a solar cell in a series array is under shadow, its current output is given by

$$
I_{s}=F I_{L}-I_{o}\left\{\exp \left(\frac{V_{D s}}{V_{t}}\right)-1\right\}-\frac{V_{D s}}{R_{\text {shs }}}
$$

Where,

$$
V_{D s}=v_{s}+I_{s} R_{\text {ses }}
$$

Similarly the current through the illuminated cells is given by equation,

Where,

$$
I_{i}=I_{L}-I_{o}\left\{\exp \left(\frac{V_{D i}}{V_{t}}\right)-1\right\}-\frac{V_{D i}}{R_{s h i}}
$$

$$
V_{D i}=v_{i}+I_{i} R_{s e i}
$$

As the shaded and illuminated cells are connected in series, the same current is forced to flow through both. So in the equations (2), (2-a), (3) and (3-a), $I_{i}$ and $I_{s}$ replaced by the same current $I_{m 2}$. Therefore,

$$
\begin{gathered}
I_{m 2}=F I_{L}-I_{o}\left\{\exp \left(\frac{V_{D s}}{V_{t}}\right)-1\right\}-\frac{V_{D s}}{R_{s h s}} \\
I_{m 2}=I_{L}-I_{o}\left\{\exp \left(\frac{V_{D i}}{V_{t}}\right)-1\right\}-\frac{V_{D i}}{R_{s h i}}
\end{gathered}
$$

As the value of $F$ decreases from 1 to $0, \exp \left(\frac{V_{D s}}{V_{t}}\right)$ tends to zero. Therefore equation (4) can be simplified as,

$$
I_{m 2}=F I_{L}+I_{o}-\frac{v_{s}+I_{m 2} R_{s e s}}{R_{s h s}}
$$

In case of series connected modules

$$
I=I_{m 1}=I_{m 2}=F I_{L}+I_{o}-\frac{v_{s}+I R_{\text {ses }}}{R_{\text {shs }}}
$$

Rearranging equation (7), the expression for the voltage across the shaded cell $v_{s}$ can be obtained as,

$$
v_{s}=\left(F I_{L}-I\right) R_{\text {shs }}-I R_{\text {ses }}
$$

The power dissipated by the shaded cell is obtained using equation (8) as

$$
P_{D s}=I \times v_{s}=I\left\{\left(F I_{L}-I\right) R_{\text {shs }}-I R_{\text {ses }}\right\}
$$

The total array output voltage is the sum of voltages across each cell operating at the same current $I$. So the array output voltage can be expressed as,

Where, $a+b=36$

$$
V=V_{m 1}+V_{m 2}=V_{m 1}+\left(v_{i}+v_{s}\right)=V_{m 1}+\left(\sum_{j=0}^{a} v_{i j}+\sum_{k=0}^{b} v_{s k}\right)
$$

In case of parallel connected modules

$$
I=I_{m 1}+I_{m 2}=I_{m 1}+\left(F I_{L}+I_{o}-\frac{v_{s}+I_{m 2} R_{\text {ses }}}{R_{\text {shs }}}\right)
$$

Rearranging equation (11), the expression for the voltage across the shaded cell $v_{s}$ can be obtained as,

$$
v_{s}=\left(F I_{L}+I_{m 1}-I\right) R_{\text {shs }}-I_{m 2} R_{\text {ses }}
$$

In equations (8) and (12) the term $I_{o} R_{s h}$ is neglected in comparison with larger terms. 
The power dissipated by the shaded cell is obtained using equation (12) as

$$
P_{D s}=I_{m 2} \times v_{s}=I_{m 2}\left\{\left(F I_{L}+I_{m 1}-I\right) R_{s h s}-I_{m 2} R_{s e s}\right\}
$$

The total module output voltage $V$ can be written as

$$
V=V_{m 1}=V_{m 2}=\left(\sum_{j=0}^{a} v_{i j}+\sum_{k=0}^{b} v_{s k}\right)
$$

Power dissipation in the shaded cell may be substantial leading to increase in its temperature. Due to increased temperature, the cell current gets concentrated in an increasingly small region of the cell, producing the hot spot. This can damage the cell encapsulation and eventually produce module failure (M. Klenk et al,2002).

Figure.2 shows the PSPICE simulation model of the series connected cells with non uniform illumination. To vary the number of cells under full illumination and shaded conditions the corresponding group diode ideality factor, reverse saturation current, $R_{s e}$ and $R_{s h}$ has been varied. i.e. the $n$ and $I_{o}$ values of $\mathrm{D}_{\mathrm{i}}$ and $\mathrm{D}_{\mathrm{s}}, R_{\text {sei }}, R_{\text {shi }}, R_{\text {ses }}$ and $R_{s h s}$. For full illumination $I_{L i}$ is fixed to $2.55 \mathrm{~A}$ and for partial shading $I_{L s}$ is varied by the factor $F$ (say $F=0.25, F=0.5$ and $F=0.75$ ). Power dissipated by the shaded cells is calculated by observing the maximum negative voltage appearing across the shaded cells multiplied by the module- 2 current. Figure.4. shows the plot between number of cells under shadow and the power dissipated by the shaded cells of series and parallel connected modules.

From Figure. 4 it can be inferred that as the proportion of shading increases, power dissipated by the shaded cells also increased. Heat dissipation in all the cases will be high when the number of cells under shaded illumination is less than that under full illumination. Moreover the power dissipated by the shaded cells is higher in series connected modules than in parallel connected modules.

From the simulation model, the power produced by the individual modules and the array power is evaluated. It is used to evaluate the mismatch power losses among cells. Mismatch power loss is the loss of available power due to series and parallel connections. It can be defined as,

$$
P_{\max (\text { mismatchlosses })}=\left(P_{\max (\bmod u l e 1)}+P_{\max (\bmod u l e 2)}\right)-P_{\max (\text { array })}
$$

Where,

$$
P_{\max (\bmod u l e 2)}=\left(\sum P_{\max (\text { illu } \min \text { atedcells })}+\sum P_{\max (\text { shadedcells })}\right)
$$

Figure.5. shows the relation between number of cells in shade and mismatch losses due to shading for different $F$. Figure.5 shows that the percentage of mismatch loss increases with decrease in $F$ as well as number of cells under shaded illumination, $b$. The mismatch power loss in series connected array is more than that of parallel connected array.

Loss of power due to series and parallel connections can also be defined in terms of utilisation factor (UF).It can be expressed as

$$
U F_{(\text {array })}=\frac{P_{\max (\text { array })}}{P_{\max (\bmod u l e 1)}+P_{\max (\bmod u l e 2)}}
$$

Figure.6 shows the UF of the module for different $b$ and F. From Figure.6 it can be inferred that the maximum power produced by the module is fully utilized when the module is with uniform illumination whether all the cells are fully illuminated or fully shaded. Utilisation of the module is poor in all the other cases.

\section{Conclusion}

Series connection of solar cells in an array is essential to get practically utilisable voltage. A number of such strings are connected in parallel to get the requisite power. As there is a substantial power loss due to non uniform illumination of a series string care should be taken to see that all the cells connected in series receive the same illumination under different patterns of shading. Such a care will give a better protection to the array and at the same time the total energy output will also be higher. In this paper, the series connected and parallel connected SPVA is compared under different shaded conditions. It is found that parallel connected SPVA is dominant under shaded condition. So, the parallel connection is the best possible configuration. The problem of high current output in parallel connected system requires the definition of new configuration.

\section{Acknowledgement}

The authors are thankful to the management of SSN college of Engineering, Chennai for providing all the experimental and computational facilities to carryout this work. 


\section{References}

Engin Karatepe, Mutlu Boztepe, Metin Colak. (2007). Development of suitable model for characterizing photovoltaic arrays with shaded solar cells. Solar Energy, pp 329-340.

Hans.S.Rauschenbach,Electrical output of Shadowed Solar Arrays. (1971). IEEE Transactions on Electron Devices, Vol,ED-18,No.8, pp 483-490

Kaushika. N.D., Gautam.N.K. (2003). Energy yield simulations of interconnected solar PV arrays. IEEE Transactions on Energy Conversion, 18(1), 2003, pp 127-134.

M.C.Alonso-García, J.M.Ruiz, W.Herrmann. (2006). Computer simulation of shading effects in photovoltaic arrays, Renewable Energy, Volume 31, Issue 12, Pages 1986-1993.

M.C.Alonso-Garcia, J.M.Ruiz. F.Chenlo. (2006). Experimental study of mismatch and shading effects in the I-V characteristic of a photovoltaic module. Solar Energy Materials \& Solar Cells 90, 329-340.

M. Klenk, S. Keller, L. Weber, C. Marckmann, A. Boueke, H. Nussbaumer, P. Fath, R. Burkhart. (2002). Investigation of the hot-spot behaviour and formation in crystalline silicon POWER cells, PV in Europe, From PV technology to energy solutions, Proceedings of the International Conference, pp. 272-275.

Quaschning.V., Hanitsch.R. (1996). Numerical Simulation of Current-Voltage characteristics of photo voltaic systems with shaded solar cells, Solar Energy, 1996,pp 56,513-520.

Ramaprabha.R. and B.L.Mathur. (2008). Modelling and Simulation of Solar PV array Under Partial Shaded conditions, Proceedings of IEEE International Conference on Sustainable Energy Technologies, pp. 12 -16, Singapore

W. Herrmann, W. Wiesner, W. Waassen. (1997). Hot spots investigations on PV modules-new concepts for a test standard and consequences for module design with respect to by-pass diodes, Proceedings of the 26th IEEE Photovoltaic Specialists Conference, pp. 1129-1132.

Woyte.A., Nijs.J., Belmans.R.(2003). Partial shadowing of photo voltaic arrays with different system configuratuins: literature review and field test results, Solar Energy 74, pp 217-233

Yingying Kuai and S. Yuvarajan. (2006). An electronic load for testing photovoltaic panels", Journal of Power Sources, Elsevier,pp 308-313.

www.cadence.com 
Table.1.Technical specifications of the solar cell and solar module used

\begin{tabular}{|c|l|c|c|}
\hline S.No. & \multicolumn{1}{|c|}{ Parameters } & Single Cell & Module \\
\hline 1 & Rated Power & $1.03 \mathrm{~W}$ & $37.08 \mathrm{~W}$ \\
\hline 2 & Voltage at maximum Power (Vmp) & $0.46 \mathrm{~V}$ & $16.56 \mathrm{~V}$ \\
\hline 3 & Current at maximum power (Imp) & $2.25 \mathrm{~A}$ & $2.25 \mathrm{~A}$ \\
\hline 4 & Open circuit voltage (Voc) & $0.59 \mathrm{~V}$ & $21.24 \mathrm{~V}$ \\
\hline 5 & Short circuit current (Isc) & $2.55 \mathrm{~A}$ & $2.55 \mathrm{~A}$ \\
\hline
\end{tabular}

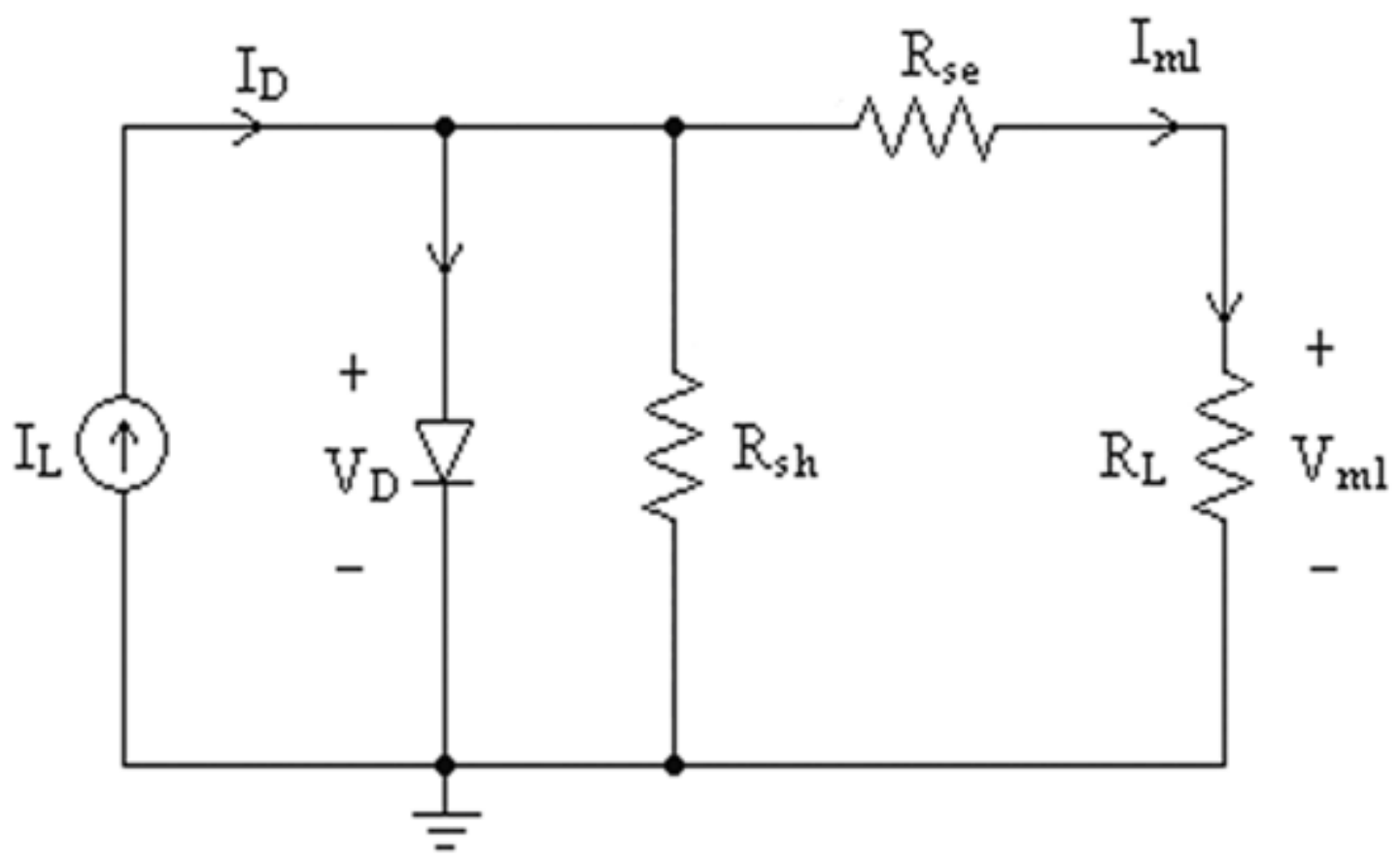

Figure 1. PSPICE equivalent circuit of SPV module consists of 36 cells in series with uniform illumination, module-1 


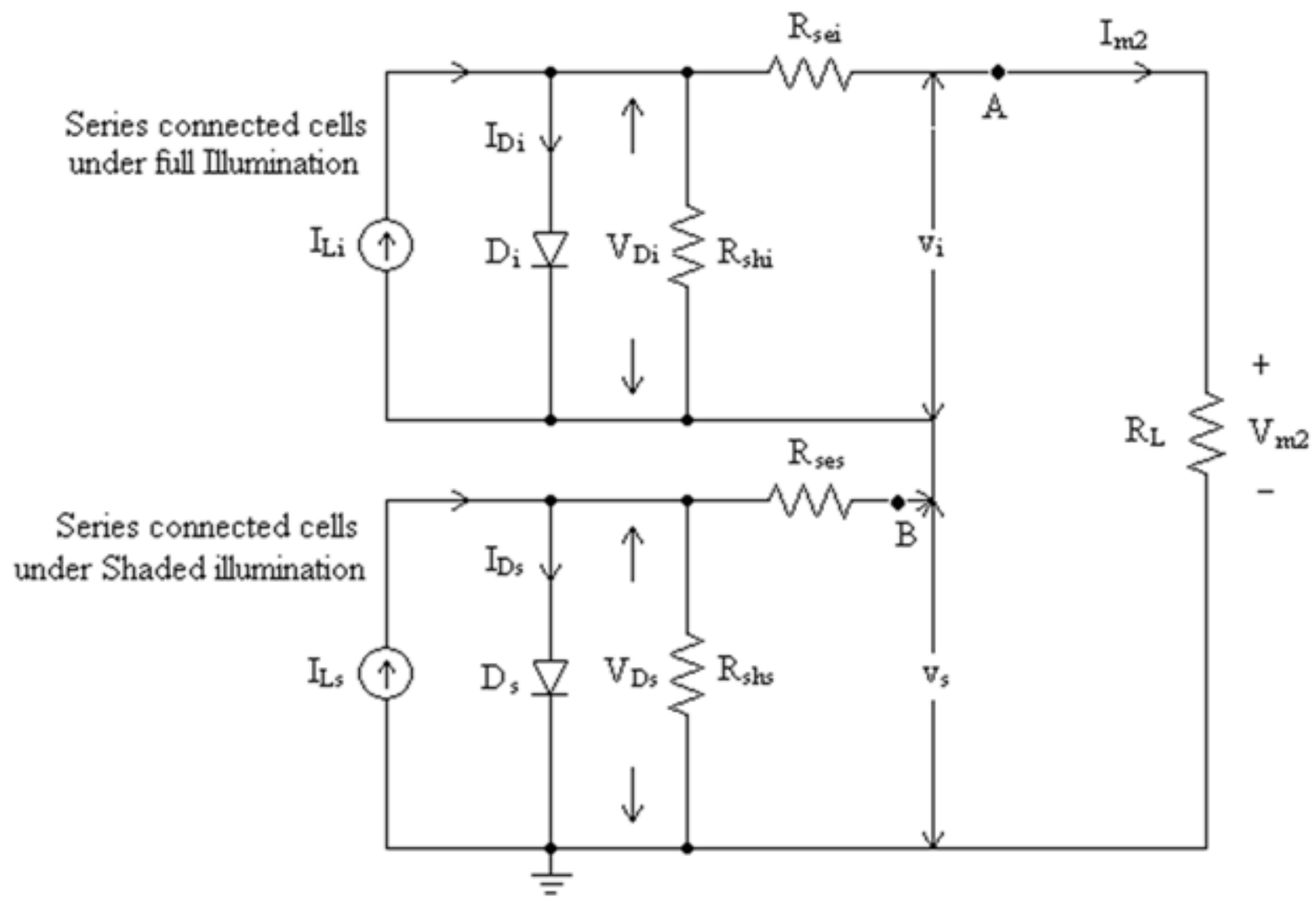

Figure 2. PSPICE equivalent circuit of SPV module consists of 36 cells in series with non uniform illumination, module-2
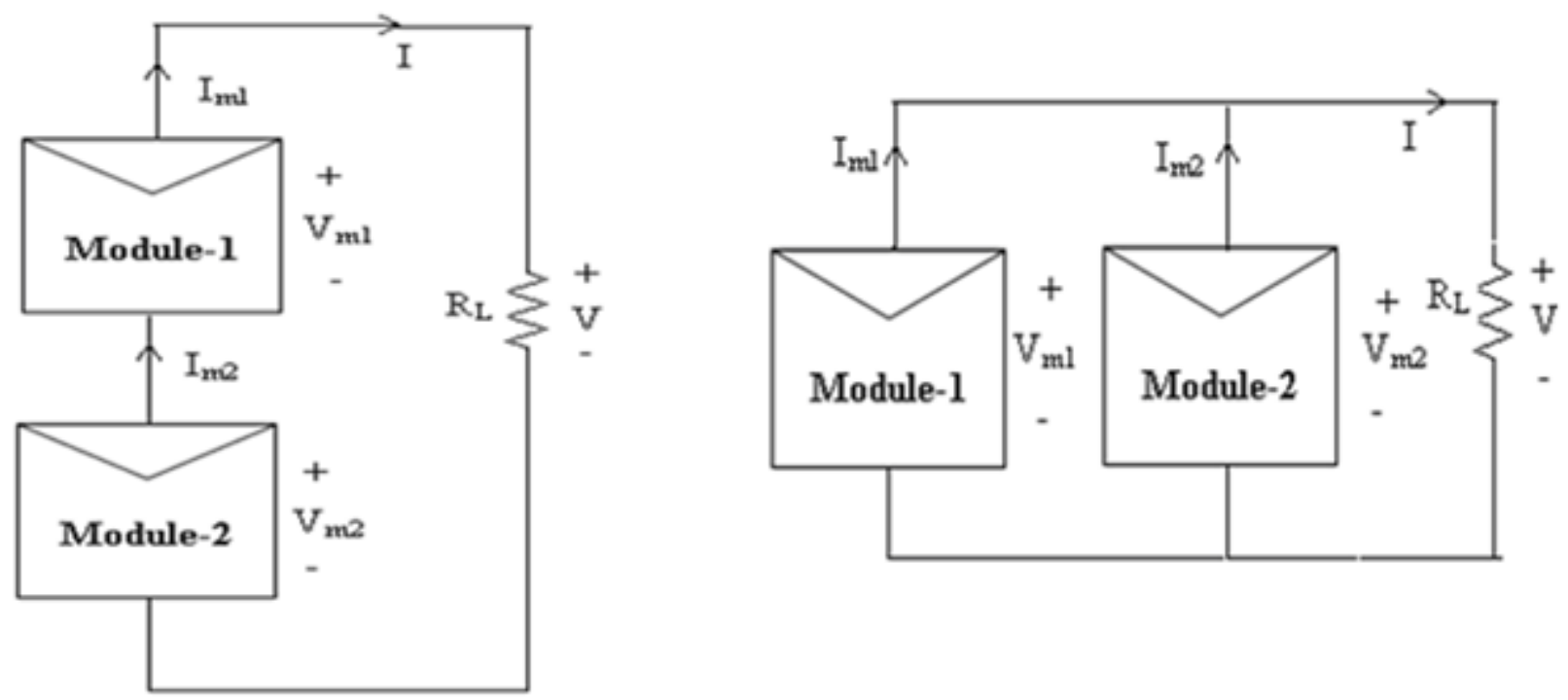

Figure 3. Series and Parallel Connected Modules 


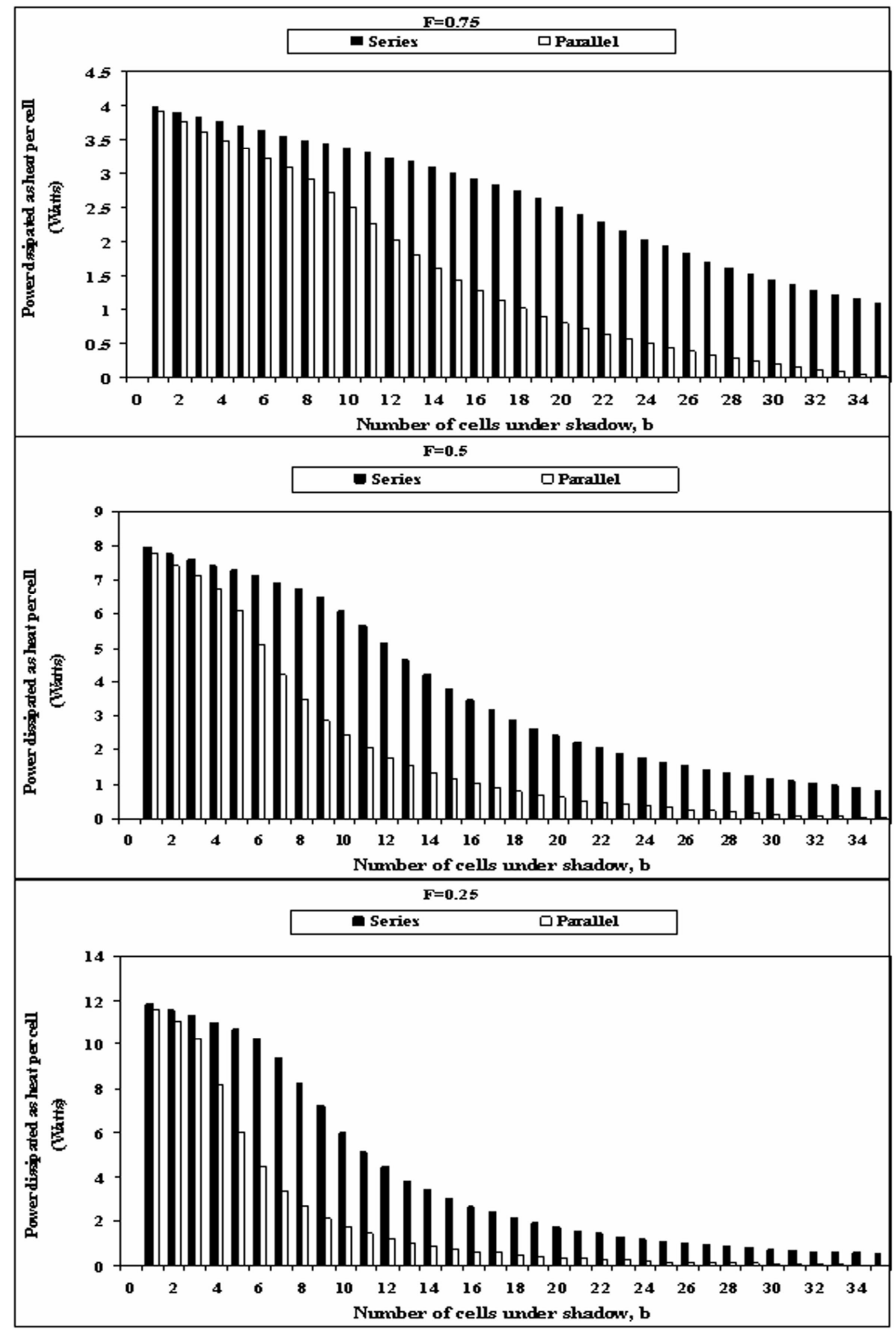

Figure 4. Relation between power dissipation $P_{D S}$ due to shaded cells ' $b$ ' as a function of $F$ of Series and Parallel connected modules 


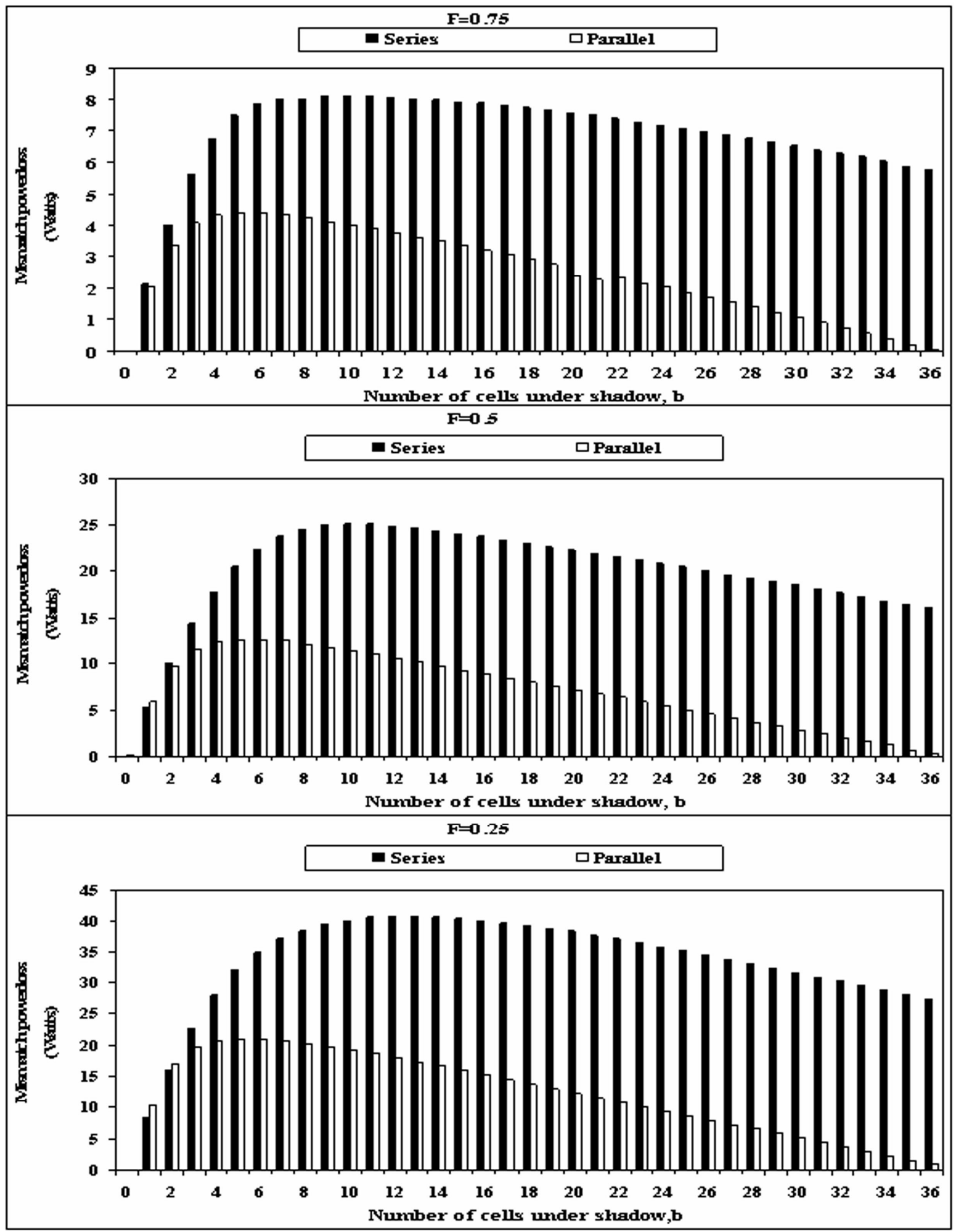

Figure 5. Comparison of Series and Parallel connected modules showing relation between the mismatch power losses and the number of shaded cells ' $b$ ' as a function of $F$ 


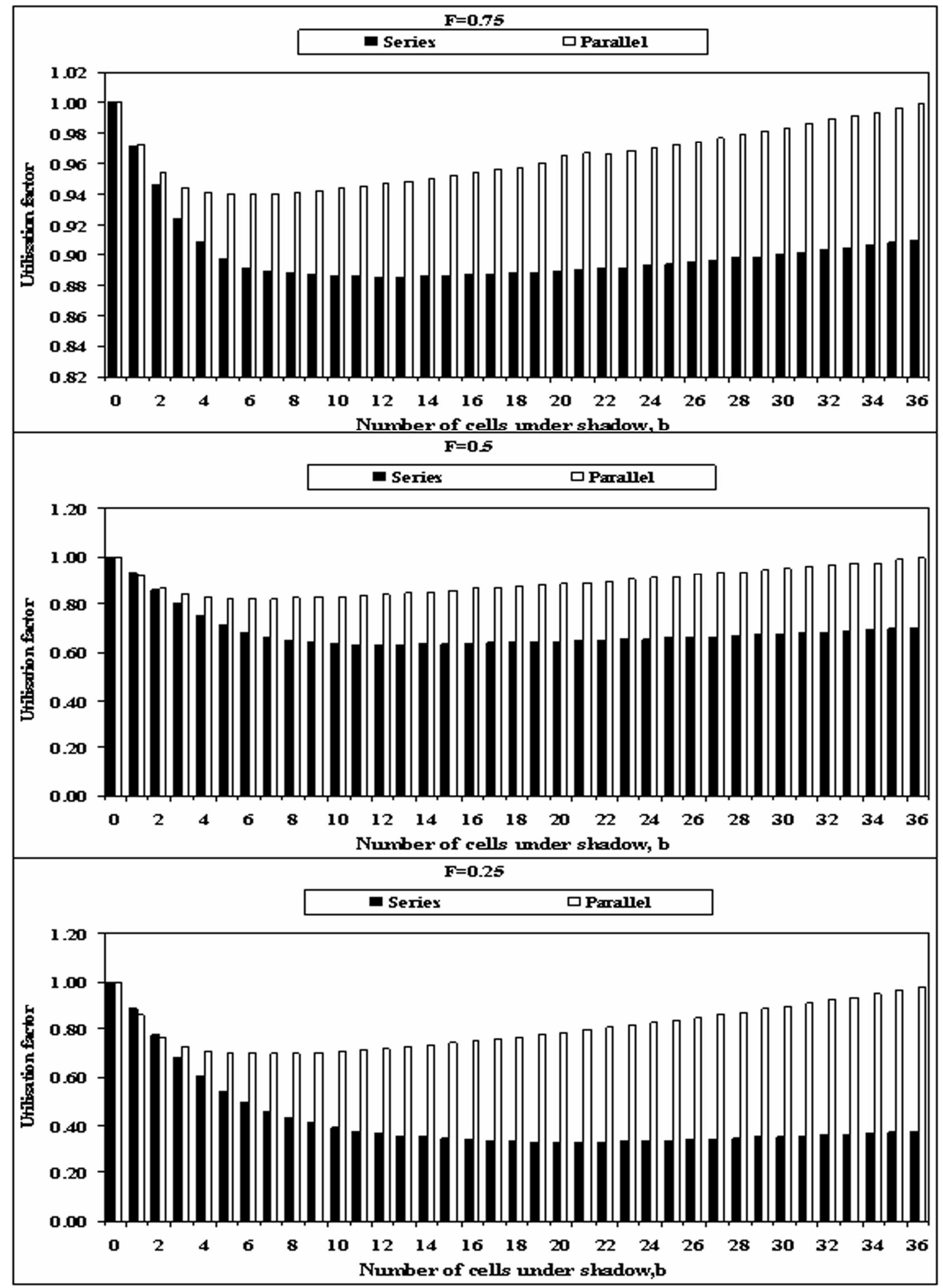

Figure 6. Relation between utilisation factor of the module and the number of shaded cells ' $b$ ' as a function of $F$ 